\title{
ImPACTO DO GlyPHOSATE AsSOCIADO COM ENDOSSUlfan E Tebuconazole SOBRE MICRORGanismos ENdossimbiontes DA SOJA ${ }^{1}$
}

\author{
Impact of Glyphosate Associated with Endosulphan and Tebuconazole on the Endosymbiotic \\ Microorganisms of the Soybean
}

\author{
REIS, M.R. ${ }^{2}$, SILVA, A.A. ${ }^{3}$, PEREIRA, J.L. ${ }^{4}$, FREITAS, M.A.M. ${ }^{5}$, COSTA, M.D. ${ }^{6}$, SILVA, M.C.S. ${ }^{7}$, \\ SANTOS, E.A. ${ }^{8}$, FRANÇA, A.C. ${ }^{4}$ e FERREIRA, G.L. ${ }^{9}$
}

\begin{abstract}
RESUMO - Objetivou-se neste trabalho avaliar o efeito do glyphosate, em aplicação sequencial, e da sua interação com endossulfan + tebuconazole na colonização micorrizica, na nodulação e nos teores de fósforo e nitrogênio foliar em plantas de soja. O experimento foi conduzido a campo em Argissolo Vermelho-Amarelo câmbico, no ano agrícola de $2007 / 08$. Foram avaliados dez tratamentos em em esquema de parcelas subdivididas, no delineamento de blocos casualizados, com quatro repetições. Nas parcelas, avaliou-se o efeito da aplicação ou não da mistura de inseticida (endossulfan) + fungicida (tebuconazole) e, nas subparcelas, o efeito dos métodos de controle de plantas daninhas (testemunha não capinada, testemunha capinada, aplicação única de glyphosate, aplicação sequencial de glyphosate e aplicação única de fomesafen + fluazifop-p-butil). A matéria seca de nódulos (MSN) e da parte aérea (MSPA), o número de nódulos (NN), a colonização micorrízica e os teores de $\mathrm{N}$ e $\mathrm{P}$ foliar foram avaliados quando as plantas de soja atingiram o estádio $\mathrm{R}_{2}$. $\mathrm{O}$ glyphosate e fomesafen + fluazifop-p-butil não reduziram a MSN de plantas de soja, exceto na presença de endossulfan + tebuconazole. O glyphosate em aplicação sequencial, na ausência de endossulfan + tebuconazole, reduziu o NN das plantas de soja em relação às plantas tratadas com inseticida + fungicida. A mistura fomesafen + fluazifop-p-butil e o glyphosate em aplicação sequencial afetaram negativamente os teores de $\mathrm{N}$ foliar em relação à testemunha capinada na ausência de endossulfan + tebuconazole, enquanto que na presença dessa mistura não se observou efeito. $O$ glyphosate não afetou a colonização micorrizica em soja tratada ou não com a mistura endossulfan + tebuconazole. Já a mistura de fomesafen + fluazifop-p-butil estimulou a colonização micorrizica na ausência da mistura endossulfan + tebuconazole. O glyphosate, em aplicação sequencial, não afetou a colonização micorrizica e a nodulação da da soja.
\end{abstract}

Palavras-chave: fungos micorrízicos, bactérias fixadoras de $\mathrm{N}_{2}$, Roundup Ready

\begin{abstract}
The objective of this work was to evaluate the effects of glyphosate, in sequential applications, and its interaction with endosulphan + tebuconazole on mycorrhizal colonization, nodulation, and leaf concentrations of $P$ and $N$ of soybean plants. The experiment was conducted in the field in a Yellow-Red Argisol in the 2007/2008 crop year. Ten treatments were installed in split plots following a randomized block design with four replications. Endosulphan + tebuconazole application was done in the main plots, while the different methods of weed control in the sub-plots (unhoed control, hoed control, single application of glyphosate, sequential application of glyphosate, single application of fomesafen + fluazifop-p-butyl). Shoot and nodule dry matter, nodule number,
\end{abstract}

1 Recebido para publicação em 14.3.2009 e na forma revisada em 12.3.2010.

2 Pesquisador do Programa Nacional de Pós-Doutorado/CAPES, Universidade Federal do Tocantins - UFT, Rua Badejós, Chácaras 69 e 72, Lt. 07, Zona Rural, Campus de Gurupi, 77404-790 Gurupi-TO, <reisagro@yahoo.com.br>; ${ }^{3}$ D.Sc., Professor Associado do Departamento de Fitotecnia, Universidade Federal de Viçosa - DFT/UFV; ${ }^{4}$ Eng$^{0}$-Agr ${ }^{\circ}$., Doutorando em Fitotecnia - DFT/UFV; ${ }^{5}$ Graduando do curso de Agronomia, Bolsista de Iniciação Científica - DFT/UFV; ${ }^{6}$ D. Sc., Professor do Dep. de Microbiologia $\mathrm{MBI} / \mathrm{UFV} ;{ }^{7}$ Bióloga, Doutoranda em Microbiologia Agrícola-MBI/UFV; ${ }^{8}$ Eng-Agr - . ${ }^{\circ}$, Mestre em Fitotecnia -DFT/UFV; ${ }^{9} \mathrm{Graduanda}$ do curso de Engenharia Florestal, Estagiária do Laboratório de Herbicidas - DFT/UFV.

Planta Daninha, Viçosa-MG, v. 28, n. 1, p. 113-121, 2010 
mycorrhizal colonization, and $N$ and $P$ concentrations were evaluated when the soybean plants reached the $R_{2}$ stage. Glyphosate and fomesafen + fluazifop-p-butyl did not cause reductions in nodule dry matter, except in the presence of endosulphan + tebuconazole. Glyphosate in sequential applications, in the absence of endosulphan + tebuconazole, promoted decreases in nodule number. Fomesafen + fluazifop-p-butyl and glyphosate in sequential applications negatively affected $N$ concentrations in the leaves compared to the hoed control, in the absence of endosulphan + tebuconazole. Glyphosate did not affect the mycorrhizal colonization regardless of the application of endosulphan + tebuconazole. However, fomesafen + fluazifop-p-butyl led to increases in the mycorrhizal colonization in the absence of endosulphan + tebuconazole. Glyphosate applied sequentially on soybean plants, under the conditions studied, did not affect the mycorrhizal colonization and nodulation.

Keywords: mycorrhizal fungi, $\mathrm{N}_{2}$-fixing bacteria, Roundup Ready.

\section{INTRODUÇÃO}

O manejo de plantas daninhas na cultura da soja exige bom nivel de conhecimento dos técnicos e produtores, em razão de essas espécies distribuirem-se de maneira heterogênea na área. Na atualidade, há também o problema de muitas espécies de plantas daninhas serem tolerantes ou resistentes a alguns herbicidas (Silva et al., 2007). Apenas para o controle de plantas daninhas em soja convencional, há 168 herbicidas diferentes disponiveis, entre marcas comerciais e distintos mecanismos de ação (Brasil, 2008). No entanto, com os objetivos de simplificar o manejo de plantas daninhas e minimizar o impacto ambiental da aplicação de agrotóxicos, desenvolveram-se cultivares resistentes a herbicidas, principalmente ao glyphosate. Esse herbicida, inibidor da enzima EPSPs (5-enol piruvil 3-xiquimato fosfato sintase), é não seletivo, relativamente barato, com amplo espectro de ação e eficiente no controle delas em estádios mais avançados, de curto efeito residual no solo e baixa toxicidade a mamíferos. Das 14 culturas resistentes a herbicidas, nove são resistentes ao glyphosate (Agbios, 2008).

Em cultivares de soja transgênica resistente ao glyphosate, dois mecanismos de resistência são relatados: 1) expressão da enzima EPSPs insensivel ao herbicida, codificada pelo gene aroA (epsps) de Agrobacterium tumefaciens CP4 (Monquero, 2005); e 2) envolve a expressão, em plantas transformadas com o gene gat4061 de Bacillus licheniformis, da enzima glyphosate $\mathrm{N}$-acetyltransferase, responsável pela degradação do glyphosate a compostos não tóxicos (Agbios, 2008).

A soja transgênica resistente ao glyphosate é a cultura que ocupa a maior área plantada no mundo, com aproximadamente 81,9 milhões de hectares. Essa área corresponde a $57 \%$ da área cultivada com culturas geneticamente modificadas no planeta. Dos 22 países que cultivam lavouras transgênicas, o Brasil apresenta a terceira maior área plantada, com 14,5 milhões de hectares cultivados com a soja transgênica e 120 mil hectares com algodão Bt, resistente a insetos (James, 2007).

Os proponentes e detentores da tecnologia dos transgênicos proclamam a redução substancial no uso de agrotóxicos, diminuindo os impactos da agricultura no ambiente. Embora não tenha reduzido a utilização desses produtos, a substituição do uso de herbicidas de alta toxicidade pelos de baixa toxicidade para animais tornou-se uma realidade, principalmente, pelo uso do glyphosate (Heimlich et al., 2000; Benbrook, 2004; Trigo \& Cap, 2006; Bonny, 2007). Apesar de o glyphosate ser considerado pouco tóxico, o uso intenso e contínuo desse herbicida em mesma área e safra de cultivo pode trazer consequências danosas e irreversiveis ao ambiente, por seus efeitos diretos e indiretos sobre organismos não alvos. Essa hipótese é justificada visto que na bula da maioria das formulações comerciais de glyphosate há informações de que o produto é perigoso ao ambiente e altamente tóxico para microrganismos do solo. Muitos microrganismos apresentam a enzima EPSPs, responsável 
pela metabolização dos aminoácidos aromáticos fenilalanina, tirosina e triptofano (Sylvia, 2005; Moreira \& Siqueira, 2006).

O glyphosate, em teoria, não altera a atividade microbiana do solo (Ferreira et al., 2006; Santos et al., 2007), devido à sua rápida inativação pela ligação do grupo fosfato presente em sua molécula aos sesquióxidos de ferro e alumínio no solo. Todavia, ao ser aplicado em planta transgênica, o glyphosate pode interferir na atividade dos microrganismos endossimbiontes - a exemplo dos fungos micorrízicos arbusculares e bactérias fixadoras de nitrogênio atmosférico presentes nas raízes de leguminosas (Sylvia, 2005; Moreira \& Siqueira, 2006). A metabolização desse composto é lenta, sendo cerca de $70 \%$ do produto absorvido rapidamente translocado para os meristemas apicais, sobretudo das raizes (Arregui et al., 2003; Neumann et al., 2006).

Os efeitos positivos da interação entre plantas cultivadas e microrganismos, especialmente fungos micorrízicos arbusculares, são relatados por diversos autores (Miranda et al., 2005; Silva et al., 2006; Sala et al., 2007) e resulta em melhor nutrição pelo fornecimento de nutrientes às plantas, principalmente, o fósforo (Sylvia et al., 2005), ainda garantindo o suprimento desse nutriente às bactérias fixadorasdenitrogênio atmosférico, no caso da soja. Vários trabalhos confirmam a interferência negativa do glyphosate sobre microrganismos fixadores de nitrogênio em plantas de soja (Santos et al., 2005, 2007; Zablotowicz \& Reddy, 2007; Dvoranen et al., 2008; Zilli et al., 2008). Os efeitos do glyphosate sobre fungos micorrizicos arbusculares na soja são pouco esclarecidos, haja vista a escassez de informação, com poucos trabalhos abordando o assunto (Morandi, 1989; Mujica et al., 1999; Malty et al., 2006). Acrescenta-se que inseticidas e fungicidas podem atingir e afetar a atividade desses microrganismos endossimbiontes, em virtude de a maioria das formulações ser sistêmica, da possível interação com herbicidas e da ação especifica dos fungicidas sobre fungos do solo.

Considerando o exposto, objetivou-se com este trabalho avaliar o efeito do glyphosate em aplicação sequencial, bem como sua interação com inseticida + fungicida, na colonização micorrízica, na nodulação e nos teores de fósforo e nitrogênio foliar em soja transgênica BRS Favorita.

\section{MATERIAL E MÉTODOS}

O experimento foi conduzido a campo na estação experimental da Universidade Federal de Viçosa, Coimbra, MG (S 20 45' 20" e W 42。 52' 40"; altitude de $700 \mathrm{~m}$ ), entre os meses de dezembro e abril, no ano agrícola 2007/08, em Argissolo Vermelho-Amarelo caracterizado fisica e quimicamente (Tabela 1).

Aos 15 dias antes da semeadura da soja, realizou-se a dessecação química da área com glyphosate + 2,4-D $\left(1.440+470 \mathrm{~g} \mathrm{ha}^{-1}\right)$, em mistura no tanque. A semeadura direta da soja BRS Favorita RR (Roundup Ready ${ }^{\circledR}$ ) foi realizada na primeira quinzena do mês de dezembro. As sementes foram tratadas com carbendazin + tiram $\left(0,30+0,70 \mathrm{~g} \mathrm{~kg}^{-1}\right.$ de sementes) e inoculadas com estirpes de Bradyrhizobium japonicum SEMIA 587 e SEMIA $5019\left(4,2 \times 10^{9}\right.$ células viáveis $\mathrm{kg}^{-1}$ de sementes). Posteriormente ao plantio, demarcaram-se 40 parcelas

Tabela 1 - Principais características físicas e químicas do Argissolo Vermelho-Amarelo cultivado com soja Roundup Ready ${ }^{\circledR}$ no período compreendido entre dezembro/2007 e abril/2008. Coimbra-MG, 2007/08

\begin{tabular}{|c|c|c|c|c|c|c|c|c|c|c|}
\hline \multicolumn{11}{|c|}{ Análise granulométrica $\left(\mathrm{dag} \mathrm{kg}^{-1}\right)$} \\
\hline Argila & \multicolumn{2}{|c|}{ Silte } & \multicolumn{2}{|c|}{ Areia fina } & \multicolumn{3}{|c|}{ Areia grossa } & \multicolumn{3}{|c|}{ Classificação textural } \\
\hline 51 & \multicolumn{2}{|c|}{13} & \multicolumn{2}{|c|}{16} & & \multicolumn{2}{|l|}{20} & \multicolumn{3}{|c|}{ Argiloso } \\
\hline \multicolumn{11}{|c|}{ Análise química } \\
\hline $\mathrm{pH}$ & $\mathrm{P}$ & $\mathrm{K}^{+}$ & $\mathrm{H}+\mathrm{Al}$ & $\mathrm{Al}^{3+}$ & $\mathrm{Ca}^{2+}$ & $\mathrm{Mg}^{2+}$ & $\mathrm{CTC}_{\text {total }}$ & $\mathrm{V}$ & $\mathrm{m}$ & $\mathrm{MO}$ \\
\hline$\left(\mathrm{H}_{2} \mathrm{O}\right)$ & \multicolumn{2}{|c|}{$\left(\mathrm{mg} \mathrm{dm}^{-3}\right)$} & \multicolumn{5}{|c|}{$\left(\mathrm{cmol}_{\mathrm{c}} \mathrm{dm}^{-3}\right)$} & \multicolumn{2}{|c|}{$(\%)$} & $\left(\right.$ dag kg $\left.^{-1}\right)$ \\
\hline 5,40 & 10,4 & 138 & 5,78 & 0 & 2,40 & 0,80 & 9,33 & 38 & 0 & 1,70 \\
\hline
\end{tabular}


(10 x $10 \mathrm{~m})$. Utilizou-se o delineamento em blocos casualizados no esquema de parcelas subdivididas, com quatro repetições. Nas parcelas, avaliou-se o efeito da aplicação ou não da mistura de inseticida + fungicida e, nas subparcelas, o efeito dos métodos de controle de plantas daninhas. As aplicações do inseticida endossulfan ( $525 \mathrm{~g} \mathrm{ha}^{-1}$ ) e do fungicida tebuconazole (150 $\mathrm{g}$ ha ${ }^{1}$ ), em mistura no tanque, foram realizadas aos 45 dias após emergência (DAE) das plântulas de soja. Os métodos de controle de plantas daninhas foram: 1 -testemunha não capinada; 2 - testemunha capinada; 3 - aplicação única de glyphosate (1.080 $\left.\mathrm{g} \mathrm{ha}^{-1}\right)$ aos $15 \mathrm{DAE} ; 4$ - aplicação sequencial de glyphosate $\left(1.080 \mathrm{~g} \mathrm{ha}^{-1}\right)$ aos 15, 30 e $45 \mathrm{DAE}$; e 5 - aplicação de fomesafen + fluazifop-p-butil $\left(180+225 \mathrm{~g} \mathrm{ha}^{-1}\right)$ aos 15 DAE. Os dados diários de precipitação pluvial, umidade relativa e temperatura média foram coletados em estação meteorológica localizada próximo à área de plantio, durante todo o período de condução do experimento (Figura 1).
As coletas de raízes para avaliações de colonização micorrízica, matéria seca de nódulos e da parte aérea das plantas de soja, número de nódulos e de folhas para os teores de $\mathrm{N}$ e $\mathrm{P}$ foliar foram realizadas quando as plantas atingiram o estádio $R_{2}(50 \%$ do florescimento pleno).

Para avaliação da colonização por fungos micorrízicos arbusculares em soja, o sistema radicular - cerca de um grama de raízes finas de oito plantas de soja por subparcela - foi armazenado em solução FAA (formaldeído: ácido acético: etanol). Posteriormente, procedeu-se à descoloração das raízes com $\mathrm{KOH}$ e coloração do material fúngico com azul de tripano, de acordo com a técnica descrita por Koske \& Gemma (1989). A taxa de colonização micorrizica foi estimada pelo método de interseção em placa quadriculada de Giovannetti \& Mosse (1980).

A nodulação foi avaliada pela contagem e secagem dos nódulos do sistema radicular de oitos plantas de soja por subparcela. Após

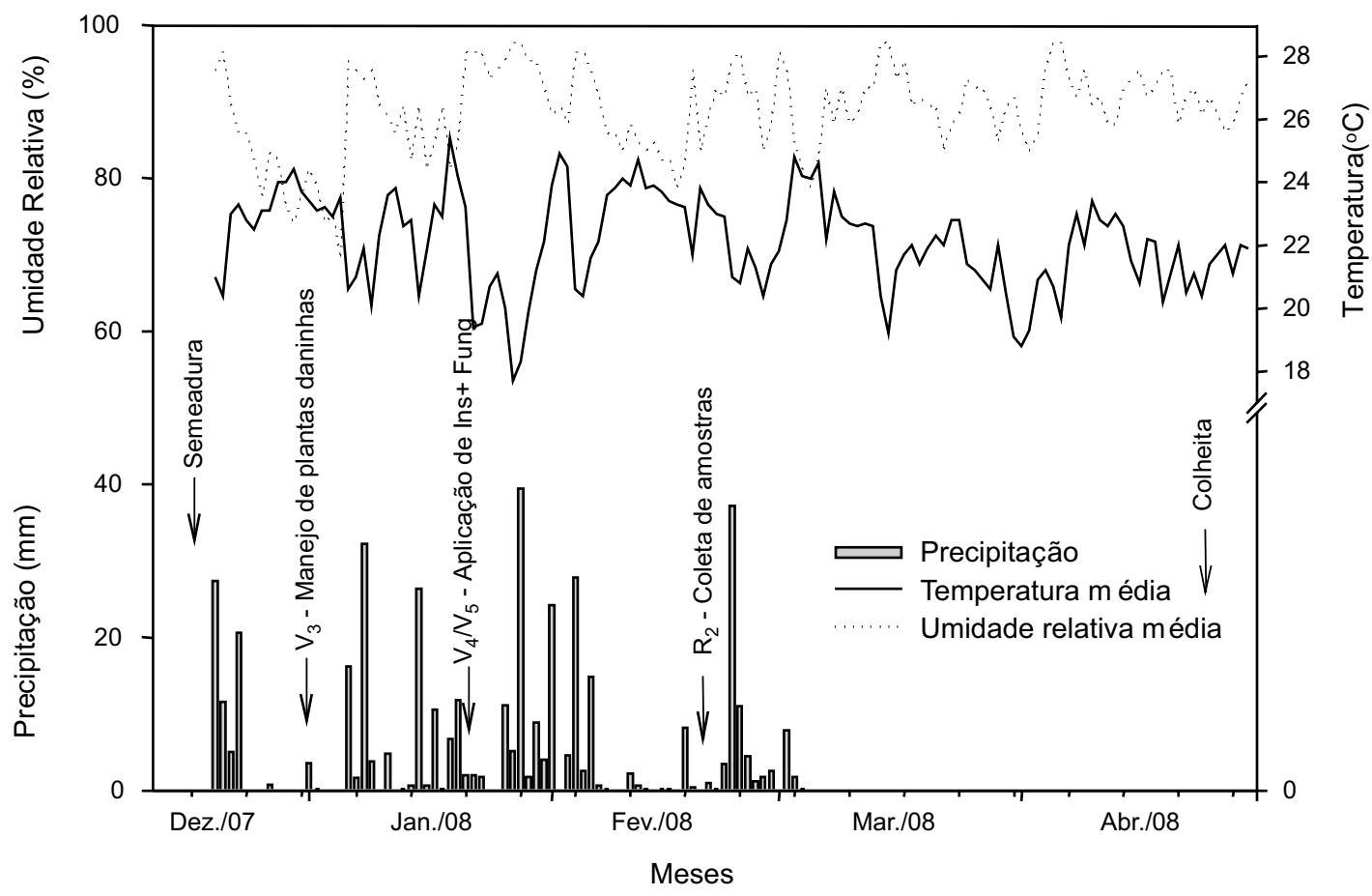
* As datas aproximadas de semeadura, manejo de plantas daninhas, aplicações de inseticidas e fungicidas e colheita estão assinaladas no
período com o respectivo estádio fenológico da soja.

Figura 1 - Precipitação pluvial, umidade relativa e temperatura diária durante o período de 12 de dezembro de 2007 a 20 de abril de 2008. Coimbra-MG, 2007/08. 
contagem, os nódulos foram submetidos à secagem, em estufa de circulação de ar forçada a $60{ }^{\circ} \mathrm{C}$ por $72 \mathrm{~h}$, e posteriormente pesados.

Para determinação dos nutrientes foliares da soja - fósforo e nitrogênio - foram coletados os terceiros trifólios, a partir do ápice, de oito plantas por subparcela. Após secagem dos tecidos vegetais, em estufa de circulação de ar forçada a $65^{\circ} \mathrm{C}$, até atingirem peso constante, elas foram moídas em moinho de lâminas. Em seguida, as amostras foram submetidas à digestão nitro-perclórica para determinação das concentrações de fósforo, pelo método da vitamina $\mathrm{C}$ modificado (Braga \& De Fellipo, 1974), e à digestão sulfúrica, para determinação do teor de nitrogênio total pelo método Kjeldahl.

Avaliações da matéria seca da parte aérea da soja no estádio $R_{2}$ foram realizadas por meio de amostragens de oito plantas por subparcela. Estas foram secas em estufa de circulação de ar forçada a $65{ }^{\circ} \mathrm{C}$, até atingirem peso constante, e posteriormente pesadas. Também foi determinada a produtividade de grãos da soja (13\% de umidade), na época da colheita, por amostragens de $10 \mathrm{~m}^{2}$ por subparcela.

Os dados foram submetidos à análise de variância $(P<0,05)$. Para comparação das médias dos tratamentos, utilizou-se o teste de Tukey $(\mathrm{P}<0,05)$.

\section{RESULTADOS E DISCUSSÃO}

Para todas as variáveis estudadas, com exceção do número de nódulos totais, observou-se a interação entre os fatores testados. Embora não se encontrem relatos na literatura dessa interação sobre associações micorrízicas e bactérias fixadoras de nitrogênio, salienta-se que o efeito de determinado herbicida sobre os endossimbiontes pode ser modificado pela combinação com outros agrotóxicos, a exemplo de inseticidas e fungicidas. Esse fato, na maioria dos trabalhos, é negligenciado ou pela falta de informação sobre a aplicação de inseticidas e/ou fungicidas para controle de pragas e doenças, respectivamente, ou pelo não estudo da interação entre herbicidas e inseticidas + fungicidas.

A matéria seca de nódulos (MSN) foi afetada negativamente pelos agrotóxicos estudados (Tabela 2). O glyphosate e a mistura fomesafen + fluazifop-p-butil não alteraram a MSN de plantas de soja na ausência da mistura endossulfan + tebuconazole (Tabela 2). Isso pode demonstrar que os herbicidas, na ausência de inseticida e fungicida, não interferiram na nodulação da soja. Bellaloui et al. (2008), ao avaliarem a influência do glyphosate em aplicação sequencial (1.120 e $3.360 \mathrm{~g} \mathrm{ha}^{-1}$, aos 28 e 42 dias após plantio, respectivamente) no metabolismo do $\mathrm{N}$ em plantas de soja, não constataram efeitos adversos desse herbicida na MSN dos nódulos. Também, Dvoranen et al. (2008) constataram que o glyphosate em aplicação única ou sequencial $(0,540$ e $0,360 \mathrm{~kg} \mathrm{ha}^{-1}$, aos 12 e 24 dias após plantio, respectivamente) não reduziu a MSN em plantas de soja BRS 254 RR cultivadas em casa de vegetação.

Por outro lado, verificou-se efeito negativo da aplicação única de fomesafen + fluazifopp-butil sobre a MSN de plantas de soja em relação à testemunha capinada na presença de endossulfan + tebuconazole (Tabela 2). Segundo Dvoranen et al. (2008), a mistura fomesafen + fluazifop-p-butil, em aplicação sequencial, não afetou a MSN da soja e foi considerada seletiva para nodulação de plantas de soja. Ressalta-se que os autores não informaram sobre a aplicação de agrotóxicos para controle de pragas e doenças.

O glyphosate em aplicação sequencial, na ausência de endossulfan + tebuconazole, reduziu o número de nódulos (NN) das plantas de soja em relação às plantas tratadas com endossulfan + tebuconazole (Tabela 2). Vários autores relataram o efeito adverso do glyphosate no número de nódulos de plantas de soja (Reddy et al., 2000; Reddy \& Zablotowicz, 2003; Zablotowicz \& Reddy, 2007; Dvoranen et al., 2008). Todavia, na presença de endossulfan + tebuconazole não foi constatado efeito negativo do glyphosate sobre o NN. O efeito protetor dessa mistura, isto é, a não redução do NN pelo glyphosate em aplicação sequencial na presença de endossulfan + tebuconazole, pode ser sugerido pela redução na população de outros microrganismos do solo; desse modo, diminui-se a competição, favorecendo a maior colonização das raízes de soja pelas bactérias fixadoras de N (Moreira \& Siqueira, 2006).

Planta Daninha, Viçosa-MG, v. 28, n. 1, p. 113-121, 2010 
Tabela 2 - Matéria seca de nódulos (MSN), número de nódulos (NN) e teor de nitrogênio foliar (N) em soja BRS Favorita RR submetida a diferentes métodos de controle de plantas daninhas com ou sem aplicação de endossulfan + tebuconazole. CoimbraMG, 2007/08

\begin{tabular}{|c|c|c|c|c|c|c|}
\hline \multirow{2}{*}{ Método de controle de plantas daninhas } & \multicolumn{2}{|c|}{ MSN (g por planta) $*$} & \multicolumn{2}{|c|}{$\mathrm{NN}(\mathrm{NN}$ por planta) $*$} & \multicolumn{2}{|c|}{$\mathrm{N}\left(\mathrm{g} \mathrm{kg}^{-1}\right) *$} \\
\hline & sem $\mathrm{E}+\mathrm{T}^{* *}$ & $\operatorname{com} \mathrm{E}+\mathrm{T}$ & sem E+T & $\operatorname{com} \mathrm{E}+\mathrm{T}$ & sem $\mathrm{E}+\mathrm{T}$ & com $\mathrm{E}+\mathrm{T}$ \\
\hline Testemunha não capinada & $0,068 \mathrm{bA}^{\frac{1 /}{}}$ & $0,124 \mathrm{bA}$ & $11,42 \mathrm{aA}$ & $21,91 \mathrm{aA}$ & $4,75 \mathrm{abB}$ & $5,23 \mathrm{aA}$ \\
\hline Testemunha capinada & $0,084 \mathrm{bA}$ & $0,172 \mathrm{aA}$ & $10,65 \mathrm{aA}$ & $22,04 \mathrm{aA}$ & $5,31 \mathrm{aA}$ & $5,02 \mathrm{aA}$ \\
\hline Aplicação única de glyphosate & $0,131 \mathrm{aA}$ & $0,165 \mathrm{aA}$ & $17,32 \mathrm{aA}$ & $23,13 \mathrm{aA}$ & $4,86 \mathrm{abB}$ & $5,40 \mathrm{aA}$ \\
\hline Aplicação sequencial de glyphosate & $0,134 \mathrm{aA}$ & $0,143 \mathrm{abA}$ & $18,77 \mathrm{aB}$ & $37,98 \mathrm{aA}$ & $4,54 \mathrm{bB}$ & $5,16 \mathrm{aA}$ \\
\hline Aplicação única de fomesafen + fluazifop-p-butil & $0,154 \mathrm{aA}$ & $0,128 \mathrm{bA}$ & $20,92 \mathrm{aA}$ & $33,48 \mathrm{aA}$ & $4,69 \mathrm{bA}$ & $4,94 \mathrm{aA}$ \\
\hline CV parcela $(\%)$ & \multicolumn{2}{|c|}{41,21} & \multicolumn{2}{|c|}{30,53} & \multicolumn{2}{|c|}{5,20} \\
\hline CV subparcela $(\%)$ & \multicolumn{2}{|c|}{16,15} & \multicolumn{2}{|c|}{18,66} & \multicolumn{2}{|c|}{4,70} \\
\hline
\end{tabular}

* Plantas de soja coletadas no estádio $\mathrm{R}_{2}$, ou seja, $50 \%$ do florescimento pleno. ** $\mathrm{E}+\mathrm{T}=$ endossulfan + tebuconazole, respectivamente.

1/ Médias seguidas pela mesma letra minúscula na coluna e maiúscula na linha, para cada variável, não diferem entre si pelo teste de Tukey $(\mathrm{P}>0,05)$

A mistura fomesafen + fluazifop-p-butil e o glyphosate em aplicação sequencial alteraram negativamente os teores de $\mathrm{N}$ foliar em relação à testemunha capinada na ausência de endossulfan + tebuconazole, apesar de ambos os herbicidas não terem afetado a MSN e o NN das plantas de soja (Tabela 2). A redução do teor de $\mathrm{N}$ em plantas de soja tratadas com glyphosate por ocasião do florescimento foi relatada por Santos et al. (2007) ao investigarem os efeitos de três formulações comerciais de glyphosate - Roundup Ready, Roundup Transorb e Zapp QI - na nutrição mineral da soja CD 219RR cultivada em casa de vegetação. Esses mesmos autores afirmaram que todas as formulações testadas reduziram os teores de $\mathrm{N}$ foliar na soja, sendo a maior redução de $\mathrm{N}$ foliar evidenciada em plantas tratadas com formulação Roundup Ready; entretanto, não foi observada redução do número de nódulos totais.

Por outro lado, não se observou efeito de herbicidas no teor de $\mathrm{N}$ foliar na presença de endossulfan + tebuconazole (Tabela 2). Verificou-se ainda que nas parcelas não tratadas com endossulfan + tebuconazole ocorreu redução nos teores de $\mathrm{N}$ foliar, com exceção observada para a testemunha capinada e a aplicação única de fomesafen + fluazifop-p-butil (Tabela 2). Nessas parcelas constatou-se incidência do fungo Phakopsora pachyrhizi (ferrugem asiática da soja) quando as plantas se encontravam no estádio reprodutivo inicial; consequentemente, isso pode ter acarretado menor acúmulo de $\mathrm{N}$ pelas plantas de soja.
O glyphosate, em aplicação única ou sequencial, não afetou a colonização micorrízica em soja tratada ou não com a mistura endossulfan + tebuconazole (Tabela 3). Os efeitos do glyphosate nas associações micorrizicas em soja são pouco elucidados (Morandi, 1989; Mujica et al., 1999; Malty et al., 2006). Com base nesses relatos, de maneira geral, o glyphosate pouco afeta os fungos micorrizicos e suas associações, porém de todos os trabalhos mencionados houve apenas uma aplicação do produto, e eles foram conduzidos ou in vitro ou em casa de vegetação com aplicação única do produto.

Já a mistura de fomesafen + fluazifopp-butil estimulou a colonização micorrízica na ausência da mistura endossulfan + tebuconazole. Contudo, esse estímulo não foi verificado em soja tratada com endossulfan + tebuconazole (Tabela 3). Contrariamente, Santos et al. (2006) relataram que a mistura fomesafen + fluazifop-p-butil reduziu a colonização micorrízica em plantas de feijão (Phaseolus vulgaris) cultivadas no sistema convencional, embora esse efeito tenha sido transiente apenas até 12 dias após a aplicação. Esses mesmos autores não verificaram tal efeito quando o feijão foi cultivado no sistema de plantio direto. Em trabalho realizado por Vieira et al. (2007), foi observada redução drástica (mais de 50\%) na colonização micorrízica em plantas de soja IAC-22 até 75 dias após aplicação do herbicida sulfentrazone. 
Ressalta-se que a mistura endossulfan + tebuconazole favoreceu a colonização micorrízica em plantas de soja, sendo essa constatação mais evidente nas testemunhas capinada e não capinada (Tabela 3 ). Uma hipótese pode estar relacionada ao fato de que, ao atingir o solo, essa mistura pode desequilibrar a população de alguns microartrópodes, a exemplo de colêmbolos, e de microrganismos do solo predadores de hifas fúngicas; desse modo, os fungos micorrízicos terão maiores chances de colonizar as raízes das plantas de soja (Moreira \& Siqueira, 2006).

Maiores teores de $\mathrm{P}$ foliar foram observados em plantas de soja tratadas com glyphosate em aplicação sequencial e a mistura fomesafen + fluazifop-p-butil em associação com endossulfan + tebuconazole (Tabela 3). No entanto, em plantas não tratadas com endossulfan + tebuconazole, verificou-se que apenas o glyphosate, em aplicação única ou sequencial, favoreceu o maior acúmulo de $\mathrm{P}$ (Tabela 3). Santos et al. (2007) não observaram alterações no teor de $\mathrm{P}$ foliar em plantas de soja tratadas com as formulações comerciais de glyphosate - Roundup Ready, Roundup Transorb e Zapp QI. Neste trabalho, a relação positiva entre micorrização e acúmulo de $\mathrm{P}$ pelas plantas não foi observada.

Todos os herbicidas avaliados reduziram a matéria seca da parte aérea da soja (Tabela 4), sendo o glyphosate em aplicação única ou sequencial o que mais afetou negativamente na ausência de endossulfan + tebuconazole, concordando com as reduções dos teores de $\mathrm{N}$ foliar (Tabela 3). Todavia, os microrganismos endossimbiontes e a produtividade da soja não foram afetados nessas parcelas (Tabelas 3 e 4).

Tabela 3 - Colonização micorrízica e teor de P foliar em soja BRS Favorita RR submetida a diferentes métodos de controle de plantas daninhas com ou sem aplicação de endossulfan + tebuconazole. Coimbra-MG, 2007/08

\begin{tabular}{|c|c|c|c|c|}
\hline \multirow{2}{*}{ Método de controle de plantas daninhas } & \multicolumn{2}{|c|}{ Micorrização (\%)* } & \multicolumn{2}{|c|}{ P foliar $\left(\mathrm{g} \mathrm{kg}^{-1}\right)^{*}$} \\
\hline & sem $\mathrm{E}+\mathrm{T} * *$ & com $\mathrm{E}+\mathrm{T}$ & sem E+T & com $\mathrm{E}+\mathrm{T}$ \\
\hline Testemunha não capinada & $56,66 \mathrm{abB}^{1 /}$ & $85,00 \mathrm{aA}$ & 3,92 aA & $3,56 \mathrm{bA}$ \\
\hline Testemunha capinada & $49,66 \mathrm{bB}$ & 76,00 aA & $3,37 \mathrm{cA}$ & 3,69 bA \\
\hline Aplicação única de glyphosate & $58,33 \mathrm{abB}$ & 76,66 aA & 3,95 aA & $3,70 \mathrm{bA}$ \\
\hline Aplicação sequencial de glyphosate & $48,33 \mathrm{bB}$ & 83,33 aA & $3,73 \mathrm{abA}$ & $4,08 \mathrm{aA}$ \\
\hline Aplicação única de fomesafen + fluazifop-p-butil & $68,33 \mathrm{aB}$ & 83,00 aA & $3,40 \mathrm{bcB}$ & $3,88 \mathrm{abA}$ \\
\hline CV parcela $(\%)$ & \multicolumn{2}{|c|}{14,01} & \multicolumn{2}{|c|}{8,71} \\
\hline CV subparcela (\%) & \multicolumn{2}{|c|}{10,08} & \multicolumn{2}{|c|}{3,70} \\
\hline
\end{tabular}

* Plantas de soja coletadas no estádio $\mathrm{R}_{2}$, ou seja, $50 \%$ do florescimento pleno. ${ }^{* *} \mathrm{E}+\mathrm{T}=$ endossulfan + tebuconazole, respectivamente.

1/ Médias seguidas pela mesma letra minúscula na coluna e maiúscula na linha, para cada variável, não diferem entre si pelo teste de Tukey $(\mathrm{P}>0,05)$.

Tabela 4 - Matéria seca da parte aérea (MSPA) e produtividade da soja BRS Favorita RR submetida a diferentes métodos de controle de plantas daninhas com ou sem aplicação de endossulfan + tebuconazole. Coimbra-MG, 2007/08

\begin{tabular}{|c|c|c|c|c|}
\hline \multirow{2}{*}{ Método de controle de plantas daninhas } & \multicolumn{2}{|c|}{ MSPA (g por planta)* } & \multicolumn{2}{|c|}{ Produtividade $\left(\mathrm{kg} \mathrm{ha}^{-1}\right)$} \\
\hline & sem $\mathrm{E}+\mathrm{T}^{* *}$ & com $\mathrm{E}+\mathrm{T}$ & sem E+T & com $\mathrm{E}+\mathrm{T}$ \\
\hline Testemunha não capinada & $13,26 \mathrm{dA}$ & $15,83 \mathrm{cA}$ & $1.943,11 \mathrm{bA}$ & $2.366,21 \mathrm{cA}$ \\
\hline Testemunha capinada & $25,83 \mathrm{aA}$ & $26,46 \mathrm{aA}$ & $2.929,80 \mathrm{aB}$ & $4.140,86 \mathrm{abA}$ \\
\hline Aplicação única de glyphosate & $18,60 \mathrm{cB}$ & $22,10 \mathrm{bA}$ & $2.391,08 \mathrm{abB}$ & $3.669,20 \mathrm{bA}$ \\
\hline Aplicação sequencial de glyphosate & $19,53 \mathrm{bcA}$ & $18,43 \mathrm{cA}$ & $2.743,91 \mathrm{abB}$ & $4.762,97 \mathrm{aA}$ \\
\hline Aplicação única de fomesafen + fluazifop-p-butil & $22,80 \mathrm{abA}$ & $19,23 \mathrm{bcB}$ & $2.964,30 \mathrm{aB}$ & $4.604,56 \mathrm{aA}$ \\
\hline CV parcela (\%) & \multicolumn{2}{|c|}{11,07} & \multicolumn{2}{|c|}{22,39} \\
\hline CV subparcela $(\%)$ & \multicolumn{2}{|c|}{6,73} & \multicolumn{2}{|c|}{11,25} \\
\hline
\end{tabular}

* Plantas de soja coletadas no estádio $\mathrm{R}_{2}$, ou seja, $50 \%$ do florescimento pleno. ${ }^{* *} \mathrm{E}+\mathrm{T}=$ endossulfan + tebuconazole, respectivamente.

1/ Médias seguidas pela mesma letra minúscula na coluna e maiúscula na linha, para cada variável, não diferem entre si pelo teste de Tukey $(\mathrm{P}>0,05)$. 
Nas parcelas não tratadas com a mistura de endossulfan + tebuconazole foram verificadas as menores produtividades (Tabela 4), haja vista a alta incidência de ferrugem asiática (Phakopsora pachyrhizi) da soja.

Embora não tenham sido observados relatos na literatura sobre a interação entre herbicidas e inseticidas + fungicidas sobre microrganismos endossimbiontes, ressalta-se que os efeitos dos herbicidas avaliados podem ser modificados na presença de endossulfan + tebuconazole. O uso do glyphosate, mesmo aplicado mais de uma vez numa mesma área durante a safra da soja, não interfere na atividade dos microrganismos endossimbiontes associados ao cultivar BRS Favorita RR. Entretanto, seu uso continuado em outros cultivares de soja transgênica precisa ser mais investigado, para melhor entendimento de sua interferência na interação soja-microrganismos.

\section{AGRADECIMENTOS}

Ao Conselho Nacional de Desenvolvimento Científico e Tecnológico (CNPq), pelo apoio financeiro para a realização deste trabalho.

\section{LITERATURA CITADA}

AGBIOS: GM Crop Database. Agbios, Ontário: 2008. Disponível em: <www.agbios.com>. Acesso em: 5 nov. 2008.

ARREGUI, M. C. et al. Monitoring glyphosate residues in transgenic glyphosate-resistant soybean. Pest Manag. Sci., v. 60 , n. 2 , p. $163-166,2004$

BELLALOUI, N. et al. Nitrogen metabolism and seed composition as influenced by glyphosate application in glyphosate-resistant soybean. J. Agr. Food Chem., v. 56, n. 8 , p. $2765-2772,2008$

BENBROOK, C. M. Genetically engineered crops and pesticide use in the united states: the first nine. Illinois: 2004. 53 p. (Biotech. Infonet Technical Paper, n. 7)

BONNY, S. Genetically modified glyphosate-tolerant soybean in the USA:adoption factors, impacts and prospects. A review. Agron. Sustain. Develop., v. 28, n. 1, p. 1-12, 2007.

BRAGA, J. M.; DE FELLIPO, B. V. Determinação espectofotométrica de fósforo em extratos de solos e plantas. R. Ceres, v. 21, n. 113, p. 73-85, 1974

Planta Daninha, Viçosa-MG, v. 28, n. 1, p. 113-121, 2010
BRASIL - Ministério da Agricultura, Pecuária e

Abastecimento. Sistema AGROFIT. Disponível em: < http:// agrofit.agricultura.gov.br/agrofit_cons/

principal_agrofit_cons $>$. Acesso em: 25 nov. 2008.

DVORANEN, E. C. et al. GR Glycine max nodulation and growth under glyphosate, fluazifop-p-butyl and fomesafen aplication. Planta Daninha, v. 26, n. 3, p. 619-625, 2008.

FERREIRA, E. A. et al. Glyphosate no controle de biótipos de azevém e impacto na microbiota do solo. Planta Daninha, v. 24 , n. 3 , p. $573-578,2006$

GIOVANNETTI, M; MOSSE, B. An evaluation of techniques to measure vesicular-arbuscular mycorrhizal infection in roots. New Phytol., v. 84, n. 3, p. 489-490, 1980 .

HEIMLICH, R. E. et al. Genetically engineered crops: has adoption reduced pesticide use? Economic Research Service/USDA, 2000. Disponível em: <http://www.ers. usda.gov/epubs/pdf/aer786>. Acesso em: 25 de out. 2008.

JAMES, C. Global status of commercialized Biotech/GM Crops: 2007. Ithaca: ISAAA, 2007. 2007. 16 p.

KOSKE, R.; GEMMA, J. N. A modified procedure for staining roots to detect VA mycorrhizas. Mycol. Res., v. 92, n. 4, p. 486-505, 1989.

MALTY, J. D. S. et al. Efeitos do glifosato sobre microrganismos simbiotróficos de soja, em meio de cultura e casa de vegetação. Pesq. Agropec. Bras., v. 41, n. 2 , p. 285-291, 2006.

MIRANDA, J. C. C.; VILELA, L.; MIRANDA, L. N. Dinâmica e contribuição da micorriza arbuscular em sistemas de produção com rotação de culturas. Pesq. Agropec. Bras., v. 40, n. 10 , p. 1005-1014, 2005.

MONQUERO, P. A. Plantas transgênicas resistentes aos herbicidas: situação e perspectivas, Bragantia, v. 64, n. 4, p. $517-531,2005$.

MORANDI, D. Effect of xenobiotics on endomycorrhizal infection and isoflavonoid accumulation in soybean roots. Plant Physiol. Biochm., v. 27, n. 5, p. 697-701, 1989.

MOREIRA, F. M. S.; SIQUEIRA, J. O. Microbiologia e bioquímica do solo. Lavras, Universidade Federal de Lavras, 2006. 729 p.

MUJCA, M. et al. Influence of the herbicides chlorsulfuron and glyphosate on mycorrhizal soybean intercropped with the weeds Brassica campestris or Sorghum halepensis. Symbiosis, v. 27, n. 1, p. 73-81, 1999. 
NEUMANN, G. et al. Relevance of glyphosate transfer to non-target plants via the rhizosphere. J. Plant Dis. Protect, v. 20, p. 963-969, 2006. (Número Especial)

REDDY, K. N.; ZABLOTOWICZ, R. M. Glyphosateresistant soybean response to various salts of glyphosate and glyphosate accumulation in soybean nodules. Weed Sci., v. 51, n. 4 , p. $496-502,2003$.

REDDY, K. N. et al. Effect of glyphosate on growth, chlorophyll, and nodulation in glyphosate-resistant and susceptible soybean (Glycine max). J. New Seeds, v. 2, n. 3, p. $37-52,2000$

SALA,V. M. R.et al. Interação entre fungos micorrízicos arbusculares e bactérias diazotróficas em trigo. Pesq. Agropec. Bras., v. 42, n. 11, p. 1593-1600, 2007.

SANTOS, J. B. et al. Avaliação de formulações de glyphosate sobre soja Roundup Ready. Planta Daninha, v. 25, n. 1, p. 165-171, 2007.

SANTOS, J. B. et al. Efeitos de diferentes formulações comerciais de glyphosate sobre estirpes de Bradyrhizobium. Planta Daninha, v. 22, n. 2, p. 293-299, 2006.

SANTOS, J. B. et al. Tolerance of Bradyrhizobium strains to glyphosate formulations. Crop Protec., v. 24, n. 6, p. $543-547,2005$.
SILVA, A. A. et al. Métodos de controle de plantas daninhas. In: SILVA, A. A.; SILVA, J. F. (Eds.). Tópicos em manejo de plantas daninhas. Viçosa, MG: Universidade Federal de Viçosa, 2007. 367 p.

SILVA, A. C. et al. Micorrização e épocas de dessecação da Brachiaria brizantha sobre o desenvolvimento da soja. Planta Daninha, v. 24, n. 2, p. 221-228, 2006.

SYLVIA, D. M. et al. Principles and applications of soil microbiology. 2.ed. New Jersey: 2005. 645 p.

TRIGO. E. J.; CAP, E. J. Ten years of genetically modified crops in argentine agriculture. Buenos Aires: ArgenBio, 2006. 52 p. Executive Summary.

VIEIRA, R. F. et al. Soil microbial biomass C and symbiotic processes associated with soybean after sulfentrazone herbicide application. Plant Soil, v. 300, n. 1, p. 95-103, 2007.

ZABLOTOWICZ, R. M.; REDDY, K. N. Nitrogenase activity, nitrogen content, and yield responses to glyphosate in glyphosate-resistant soybean. Crop Protec., v. 26, n. 3, p. 370-376, 2007.

ZILLI, J. E. et al. Efeito de glyphosate e imazaquin na comunidade bacteriana do rizoplano de soja (Glycine max (L.) Merrill) e em características microbiológicas do solo. R. Bras. Ci. Solo, v. 32, n. 2, p. 633-642, 2008. 